\title{
MJMR EXPERIENCE OF HOMESICKNESS AND COPING STRATEGIES AMONG MALAYSIAN YOUNG ADUTLS
}

\author{
Lee Kia Ting', Mohtaram Rabbani ${ }^{1 *}$, Ali Zahabi ${ }^{2}$ \\ ${ }^{1}$ UCSI University, Kuala Lumpur, Malaysia \\ ${ }^{2}$ Lecturer, School of Language and General Education, Walailak University, Thailand \\ Corresponding Author's E-mail: mohtaram@ucsiuniversity.edu.my
}

\begin{abstract}
The aim of this research is to explore the young adult's perception of homesickness and coping strategy. Young adults who experience homesickness will tend to use two types of coping strategies, which they are problem focused coping and emotion focused coping. This research was conducted among 5 Malaysian young adults. The age range for participants were 19-26 years old, they all experienced homesickness and came from another state or city to Kuala Lumpur to study. The recruitment and research conducted in Kuala Lumpur. This research was conducted through a semi-structured interview by using interview questions. Thematic analysis was used to analyze the data collected. The results showed that there are 7 areas that participants report missing about their home when experiencing homesickness, such as activity, animal, family, feeling and others. Besides, psychological and emotional effects were found among young adults who experience homesickness. Lastly, the coping strategy used by young adults to deal with homesickness can be concluded into two, which they are problem focused coping strategy and emotion focused coping strategy. More importantly, seeking for social support is the most common way for young adults to deal with homesickness.
\end{abstract}

Keywords: Coping Strategy, Homesickness, Young Adults

\section{INTRODUCTION}

At certain stage in life, young adults are forced to separate from their parents and friends to a new and unfamiliar place due to the demands of work or education. This transition is meant a lot for the young adults since this is their first prolonged period away from home (Beck, Taylor, \& Robbins, 2003). For some of the young adults, they have no trouble in adapting to the new environment or during the process of adjustment. But some of the young adults may not be the same. Some of the young adults are incapable to deal with the shift due to it could be difficult and unbearable to them. So, when young adults are having difficulties in adjusting to the new environment, they may experience prolonged homesickness (Uchenna, C. Onuoha, Opeyemi \& I. Segun-Martins, 2013). This long-lasting feeling of homesickness could affect their life in different ways.

\section{Problem Statement}

Some define homesickness as the discomfort or impairment lead by the actual or anticipated separation from home (Thurber \& Walton, 2012). However, the American Psychiatric Association define homesickness as an anxiety disorder, which includes cognitive thinking that is focusing on the home (Scharp, Paxman, \& Thomas, 2015). Homesickness also explain as the distress when a person forced to leave or separate with home and the significant ones like family and friends (Uchenna, C. Onuoha, Opeyemi, \& I. Segun-Martins, 2013). Although, there are a lot of definition given by researcher and all these conceptualizations surrounding the concept of home, but none of the researchers go and identify what home really refers to for a homesick person. For example, when a person talks about home, he or she may refer to the pets, the family members, and even the feelings when being at their home (Scharp, Paxman, \& Thomas, 2015). In other word, which kind of thing or person will trigger the young adults to experience homesickness.

Homesickness could occur among all people regardless 
their age, but it mostly happens in children and young adults when they are forced to leave their past environment, such as their former school or former neighborhood (Azizi, 2015). About $60-70 \%$ of young adults have the feelings of homesickness when they are forced to leave their home and move in the hostel in the university (Nijhof \& Engles, 2007). It is also reported that 69 percent of young adult's report feeling of homesickness and it causes them some troubles in school performance, and some physical health concerns. The experience of homesickness, such as the effect can be varied among everyone (English, Darvis, Wei, \& Gross, 2017). Some may experience it in physical, emotional, social or psychological way (Biasi, et al., 2018). Research shows that homesickness could cause young adults to have difficulties in concentration and problem solving (Thomas, 2018). Apart from that, it could affect the young adults emotionally like feeling sad or cry when thinking about home. These symptoms might lead them to experience depression and anxiety (Azizi, 2015). Moreover, feeling of isolation and withdrawal from the society could be one of the experiences of homesickness too (Robsham, 2016). Apart from that, young adults who reported experiencing homesickness have been found out of psychological disturbance, such as poor academic performance and other related issues(Khushde, Farhangi, Kouteh, Kahrazei \& Ziapour, 2017). It was reported that most of the young adult's mentioned that they have the feeling of nervousness, anxiety, feeling sad and most commonly, obsessive preoccupation with the thinking of home when experiencing homesickness (Ho, 2010). Lastly, homesickness could cause an individual to feel sick and experience headache (Mozafarinia \& Tavafian, 2014). Although, homesickness has a big impact on young adults' life, but this issue is still not getting enough of attention from the society (Scharp, Paxman, \& Thomas , 2015). For instance, although homesickness has been found bringing painful and negative impact on a person's life, it hasn't been defined as a formal diagnostic term. Moreover, research found out that homesickness is no longer categorized as a mental disorder anymore in either fourth or fifth edition of the Diagnostic and Statistical Manual of Mental Disorder (Stroebe, Schut, \& Nauta, 2015). This will cause homesickness to be ignored and not getting enough of attention by the society since homesickness is considered as an emotional woe rather than a mental disorder. So, it is important to take experience of homesickness into consideration and raise the awareness of it in society since this issue has a big impact on young adult's life.

Some factors contribute to experiencing homesickness among young adults have been identified by researchers. For instance, missing the family members or friends (Nijhof \& Engles, 2007), lack of social support (Sun, 2015), attachment style and the relationship between young adults and their parents (Uchenna, C. Onuoha, Opeyemi, \& I. Segun-Martins, 2013). Some research also found out that lack of social connectedness and low perceive of sense of belonginess in the society will cause a person to experience homesickness. The theory behind it is an individual will feel secure when he or she feels that they are accepted by the society or the community (Thomas, 2018). Last but not least, one of the most important factors discovered by the researcher is lack of coping strategy (Karen, 2009). This is because the young adults have no clue on how to deal with the feelings of homesickness effectively.

When it comes to dealing with homesickness, coping strategy could be an excellent suggestion given by researcher (Hack-Polay, 2012). Coping strategy is described as the action taken by an individual in response to reduce the negative effects of the appraised stressor (Lian \& Tam, 2014). Two types of effective coping strategy had been identified by researcher to deal with homesickness, which they are problem focused coping strategy and emotion focused coping strategy (Nijhof \& Engles, 2007). Problem focused coping strategy is described as the process of which an individual focus on trying to reduce the stressor that leads to a problem while the stressor is still within the control area, for example, do some research about the related issue or stressor to obtain information about it, adapting new skills to control it, or do a pro-and-con list to decide which decision is the best. In contrast, emotion focused coping is more into managing the emotion retrieved from an uncontrivable stressor. For example, controlling the feelings inside, relaxation technique such as yoga and seeking social support which is the most common coping skill used by young adults who experience homesickness (Saigal, 2017). Problem 
focused coping is more towards active way of coping while emotion focused coping is more towards passive way of coping. Still, as mentioned before, lack of coping strategy could cause young adults to experience higher level of homesickness, so it is important for the researcher to prevent this issue happens by providing the knowledge of the use of coping strategy.

A few problem statements can be made from all the information mentioned above. Firstly, the low level of homesickness awareness among the society still exiting even though nearly every individual will experience homesickness at some moments in their lives (Sun, Hagedorn, \& Zhang, 2016). The research will remind the society that homesickness is a mental disorder rather than just an adjustment problem or emotional woe. In other words, the impact of homesickness can be severe and serious, so the society should view it as a serious issue. Then, lack of coping strategies among young adults has been considered as one of the factors contribute to high level of homesickness (Kegel, 2009). To improve this situation, raise of awareness regarding coping strategy among young adults must be done to provide an understanding of what actions should be taken to deal with homesickness. Apart from that, none of the researcher try to identify what "home' really refers to for a homesick person. In other words, what kind of things or persons in home might trigger a person to experience homesickness. Lastly, lack of qualitative research to explore about homesickness and coping strategy can be found let alone qualitative research found in Malaysia. So, it is important for the researcher to find out the homesickness experience and coping strategy used among Malaysian young adults to improve their life.

\section{METHODOLOGY}

Qualitative research design was used in this research to investigate how respondents experience some aspects of their lives, an event or situation, how they behave and fiction and to explore a social problem in depth (Teherani, Martimianakis, Stenfors-Hayes, Wadhwa, \& Varpio, 2015).Semi-structured interview was used to obtain the information about the homesickness experience and coping strategy used to deal with it among young adults. Then, transcendental phenomenological research approach has been chosen as it allows the researcher to study and understand a specific phenomenal and how human perceive it (Sheehan, 2014).

The sample characteristics set by the researcher were Malaysian young adults who experience homesickness, ages between 19-26 years old, came from another state or city to Kuala Lumpur to study. The sample size for this research was 5 participants for the main study and 1 for the pilot study. The recruitment and research took place in Kuala Lumpur. In order to save the time and cost of the researcher in finding sample, purposive sampling has been chosen since only those specific qualities that participant possesses will be considered and selected (Etikan, Musa, \& Alkassim, 2015). But a screening activity was conducted before using purposive sampling to determine the eligibility of participant in the research (Amherst, 2015). Instrument used in this research was a list of interview questions adapted from other research's regarding homesickness and coping strategy used were modified to suit this research. Then thematic analysis was used to analyze the data.

The researcher recruited sample in Kuala Lumpur area Then a screening activity was conducted. In this step, informed consent was given to participant. After that, purposive sampling technique is applied. After appointment made, interview session was conducted in Kuala Lumpur. Lastly, the data were analyzed by using thematic analysis approach.

\section{RESULTS}

There were 5 participants in this research, 4 Malaysian Chinese male and 1 Malaysian Chinese female. All of them were studying in university located in Kuala Lumpur area and they were living with their friends or housemates. The age range among them was 21-26. In the results, 3 main themes were formed to answer the 3 research objectives, which they are 1) meaning of home, 2) perceived effects of homesickness, and 3) ways of coping.

The first objective set by the researchers is to find out what do young adults report missing about their home when experiencing homesickness. From the results, the researcher discovered that there are 7 aspects or areas that young adults report missing about their home when they are homesick, which they are activity, animal, family, feeling, food, friend and safety. Not only that, 
they have been found out that at least one out of these 7 areas that they will miss about when they are homesick. More importantly, family is the area that participants reported missing about when homesick.

The second objective set by researchers is to find out what is the young adult's perception of homesickness, or simply means the effect of it. From the results, the researcher found out that homesickness will influence them emotionally and psychologically. For example, participants reported that they felt sad and depressed when experiencing homesickness. Moreover, they felt stress and unable to focus or concentrate too. However, physical and social affect didn't report by participants.

The last objective set by researcher is to find out the coping strategy that young adults used to cope with homesickness. From the results, the researcher categorized different strategies into two categories or sub-theme, which they are the problem focused coping strategy and emotion focused coping strategy. Seeking for social support is the most common way used by participants to deal with homesickness. Only few participants stated that they used emotion focused coping strategy like writing diary and exercise to cope with homesickness.

\section{DISCUSSION}

\section{Homesickness and Coping strategy}

Homesickness, by definition is the discomfort or impairment lead by the actual or anticipated separation from home (Thurber \& Walton, 2012). In this research, it was found out that 7 aspects or areas that young adults report missing about their home when they are homesick which is similar to the result from previous research (Scharp, Paxman, \& Thomas , 2015).From here, we are able to know that when young adults report missing home, he or she may refer to family, food, pet and other aspect areas mentioned in the result part.

The second finding is the effect of homesickness. As mentioned before, homesickness can affect a person in physically, socially, psychologically or emotionally (Biasi , et al., 2018). In this research, only emotion and psychological can be discovered which is not consistent with the previous research.

Lastly. the coping strategy used by young adults when they are homesick is consistent with previous research which identified problem focused coping strategy and emotion focused coping strategy are two of the effective way to deal with homesickness (Nijhof \& Engels, 2007). Not only that, seeking for social support is the most common way used by young adults when they are homesick in which this result is consistent with previous research too.

\section{Limitations and Recommendation of Study}

There are always some limitations in a research, same goes to this research too. First limitation can be found in this research is it only took place in Malaysia by participating Malaysia young adults thus the findings from this research may not be able to apply to other research conduct in another country. Lastly, 5 participants were participated in this research which is considered as a small number of participants. A larger number of participants will be better for this research since it could produce more accurate result, adequate representation of the population and valid evidence in the conclusion.

Some recommendations for future researcher will be more participants should be recruited to gain a large amount of data. In that way, newly information may be discovered through the research. Besides, it is encouraged to use participants outside of Kuala Lumpur area or Malaysia so that the result can be applied on all the young adults. Lastly, gender should be considered as one of the variables too.

\section{Implication of Study}

Through this research, the society, specially for the young adult can learn about the impact of homesickness and ways to handle it. In that way, they can be aware of the seriousness of homesickness, in other words, raising awareness and they are able to learn about the effective ways to deal with homesickness. Moreover, stress level may be reduced among young adults who experiencing homesickness. Other than that, the parents and school party can be beneficial as they will pay more attention to their children or students and able to provide the help that needed for them.

For other researchers, the results can contribute meaningful knowledge to them who also in this field. The results show that the impact of homesickness may 
be different. This gives other researchers a chance to explore more about how the impact is different. Besides that, the meaning of home can be different as well. Other researchers should continue to explore more about it in depth. The theory explained in this research which was, the transactional model of stress and coping theory can be used to describe well about the process of homesickness and coping strategy.

\section{CONCLUSION}

In conclusion, the meaning of the home may be different to each individual, so does the effect of homesickness. Results shows that the most common strategy used to solve homesickness is seeking for social support, followed by emotion focused coping strategy. Then, the theory used in the research able to explain process of experiencing for homesickness. Moreover, by doing this research able to raise the awareness of homesickness to the society including young adults along with other practical benefits too. There are some limitations in this research too, for example, like the number of participants, short amount of time and young adults from another country or state should be included as well. Some recommendations like more participants should be recruited.

\section{CONFLICT OF INTERESTS}

The authors declare that they have no conflict of interest.

\section{REFERENCES}

Azizi, S. (2015). Relationship between Homesickness and Test Anxiety in Non-Native Students of Shiraz University of Medical Sciences International Branch in the Clinical and Physiopathology Course In 2013. Global Journal Of Health Science, 8(7), pp:293-300.

Beck, R., Taylor, C., Robbins, M. (2003). Missing Home: Sociotropy and Autonomy and Their Relationship To Psychological Distress and Homesickness in College Freshmen. Anxiety, Stress, and Coping, 16(2), 155166. doi:10.1080/1061580021000056979

Biasi, V., Mallia, L., Russo, P., Menozzi, F., Cerutti, R., \& Violani, C. (2018). Homesickness Experience, Distress and Sleep Quality of First-Year. Journal of Educational and Social Research, 8(1), pp:9-17.
English, T., Darvis, J., Wei, M., \& Gross, J. J. (2017). Homesickness and Adjustment Across the First Year of College: A Longitudinal Study. Emotion, 17(1), pp:1-5.

Hack-Polay, D. (2012). When Home Isn't Home - A Study of Homesickness and Coping Strategies among Migrant Workers and Expatriates. International Journal of Psychological Studies, 4(3), pp:62-72.

Ho, D. (2010). Homesickness isn't really about 'home'. Retrieved from CNN: http://edition.cnn.com/ 2010/HEALTH/08/16/homesickness.not.about.hom e/index.html?fbclid=IwAR1B81XDpu2MJqOHMz WkpwIf6x mBKivAag 0 SzJ 1 1 R 4 R RdwnhYcCrdVb3zI

Kegel, K. (2009). Homesickness in International College Students. Compelling Counseling Interventions, 5(2), pp:67-76

Khushde, S., Farhangi, M., Kouteh, B.R., Kahrazei, F., \& Ziapour, A. (2017). A comparative study of homesickness, depression, and internet addiction between native and nonnative students at University of Sistan and Baluchestan, Iran. Annals of Tropical Medicine and Public Health, 10(6), pp:1537-1546.

Lian, S.-Y., \& Tam, C. L. (2014). Work Stress, Coping Strategies and Resilience: A Study among Working Females. Asian Social Science, 10(12), 41-52. doi:10.5539/ass.v10n12p41

Mozafarinia, F., \& Tavafian, S. S. (2014). Homesickness and Coping Strategies among International Students Studying in University Technology Malaysia. Health Education and Health Promotion, 2(1), 53-61.

Nijhof, K. S., \& Engels, R. C. (2007). Parenting styles, coping strategies, and the expression of homesickness. Journal of Adolescence, 30(5), pp:709-720.

Robsham, K. (2016). The Impact of Student Involvement on Homesickness. Retrieved from: http://www. presence.io/blog/the-impact-of-student-involvementon-homesickness/ ?fbclid=IwAR2SGk2S1sde3Y19oezJL87 A0UQWT5H0dK1s9EKAxn WiSUSRIGLSZS2Rbw 
Saigal, E. (2017). Problem, Emotion, and Appraisal Focused Coping Strategies. The Institute For Life Coach Training. Retrieve from: https://www. lifecoachtraining. com/blog/entry/problem emotion_and_appraisal_focused_coping_strategie $\mathrm{s}$

Scharp, K. M., Paxman, C. G. \& Thomas, L. J. (2015). "I Want to Go Home": Homesickness Experiences and Social-Support-Seeking Practices. Environment and Behavior, 48(9), pp:1175-1197.

Sheehan, S. (2014). A Conceptual Framework for Understanding Transcendental Phenomenology Through the Lived Experiences of Biblical Leaders. Emerging Leadership Journeys, 7(1), 10 20.

Stroebe, M., Schut, H., \& Nauta, M. H. (2015). Is Homesickness a Mini-Grief? Development of a Dual Process Model. Clinical Psychological Science, 4(2), pp:344-358.

Sun, J. (2015). Homesick at college: a predictive model for first year first-time students. Graduate Theses and Dissertations, 4(1), pp:1-108.

Sun, J., Hagedorn, L. S., \& Zhang, Y. (2016). Homesickness at College: Its Impact on Academic Performance and Retention. Journal of College Student Development, 57(8), pp:943-957.

Teherani, A., Martimianakis, T., Stenfors-Hayes, T., Wadhwa, A., \& Varpio, L. (2015). Choosing a Qualitative Research Approach. Journal of Graduate Medical Education, 7(4), pp:669-670.

Thomas, D. (2018). Factors that contribute to homesickness among students in Thailand. Journal of Social Sciences, 2018(7) pp:1-6.

Thurber, C. A., \& Walton, E. A. (2012). Homesickness and adjustment in university students. Journal of American college health, 60(5), pp:1-5.

Uchenna, C. Onuoha, Opeyemi, \& I. Segun-Martins. (2013). Self efficacy,Self esteem, and Gender As Factors Predicting Homesickness of Freshmen. African Journal for the Psychological Study of Social Issues, 60(5), pp:263-270. 